\title{
Cristología del Evangelio de Marcos*
}

\section{César Carbullanca-Núñez ${ }^{* *}$ Paulo Augusto de Souza Nogueira***}

RECIBIDO: 21-07-16. APROBADO: 13-12-16

Resumen: El artículo estudia la cristología del Evangelio de Marcos y su relación con el sentido de la muerte de Cristo. Sostendremos que el sentido de la muerte de Cristo se basa en una inversión escatológica, según la cual los impíos no comprenden los misterios del Reino, y que paradójicamente dicho conocimiento es dado a los elegidos. Esta inversión es tomada de tradiciones apocalípticas que son radicalizadas en la cristología del evangelista, en diversas partes del Evangelio de manera especial en la epistemología que subyace a la tradición de la pasión del Justo, el Hijo del Hombre, pues sus sufrimientos y muerte representan un cambio en el estatuto epistemológico del sufrimiento del Justo y del lugar donde Dios se revela al hombre.

Palabras clave: Evangelio de Marcos, cristología, mesianismo, cruz, martirio, muerte, epistemología bíblica.

\section{Christology of the Gospel of Mark}

Aвstract: The article analyzes the Christology of the Gospel of Mark and its relation with the meaning of the death of Christ. We will hold that the meaning of Christ's death is based on an eschatological inversion according to which the ungodly people do not understand the mysteries of the Kingdom, a knowledge that is paradoxically given to the chosen ones. This inversion is taken from apocalyptic traditions that have been radicalized in the Christology of the evangelist, in several parts of the Gospel, especially in the epistemology present in the tradition of the passion of the Righteous, the Son of Man. The sufferings and death of the Son of Man represent a change in the epistemological status of the suffering of the Righteous and of the place where God reveals himself to man.

Key Words: Gospel of Mark, Christology, Messianism, Cross, Martyrdom, Death, Biblical Epistemology.

PARA CITAR ESTE ARTÍ́CULO:

Carbullanca Núñez, César y Paulo de Souza Nogueira. "Cristología del Evangelio de Marcos". Theologica Xaveriana 184 (2017): 333-359. https://doi.org/ 10.11144/javeriana.tx67-184.cem

* Articulo producto de la investigación Fondecyt 1120029, "El martirio del Hijo del Hombre: estudio de tradiciones judías y su influencia en los evangelios canónicos".

** César Carbullanca Núñez: Doctor en Teología Bíblica, Pontificia Universidad Comillas, Madrid, España. Investigador y docente, Facultad de Ciencias Religiosas y Filosóficas, Universidad Católica del Maule; y director Centro de Documentación e Investigaciones Religioso-Pastorales. OrCid: 0000-00029346-3543. Correo electrónico: carbullanca@yahoo.com

*** Paulo Augusto de Souza Nogueira: Doctor en Teología, Ruprecht-Karls-Universität Heidelberg, Alemania. Profesor titular, Universidad Metodista, Sao Paulo. OrCID: 0000-0003-2781-6942. Correo electrónico: paulo.dsn@uol.com.br 


\section{Introducción ${ }^{1}$}

La discusión en torno de la cristología marcana, en la primera mitad del siglo pasado, estuvo centrada en el denominado secreto mesiánico; pero la situación ha variado considerablemente a partir de los descubrimientos de Qumrán y de la publicación de escritos sobre la mesianología judía, al impulsar el estudio de la cristología marcana e integrar nuevos datos con que se cuenta.

El punto de partida del presente artículo es el new look de los estudios sobre la cristología de Marcos, para mostrar que la cuestión mesiánica en el Evangelio de Marcos se inscribe en un horizonte escatológico del arribo del eschaton, y en este contexto se pregunta por el modo como se entiende la mediación del profeta-mesías.

Como han hecho notar E. Schweitzer y A. Weihs's, el Evangelio de Marcos expresa su cristología como una radicalización de la escatología apocalíptica. En especial, en la segunda parte del artículo sostendremos que, a partir de la tradición martirial de la pasión del Justo presente en el Evangelio de Marcos, el evangelista expone la figura del Hijo del Hombre de acuerdo con una inversión escatológica propia de grupos apocalípticos judíos.

Esta contiene dos aspectos: en primer lugar, una cuestión axiológica, es decir, Dios elige a los pobres y humillados como paradigmas de humanidad, reconociendo sus derechos y su estatuto de persona; en segundo lugar muestra una cuestión epistemológica: la revelación de los misterios divinos es dada a los elegidos y negada a los impíos ${ }^{3}$. Esta inversión escatológica producto del pecado explica que el plan divino se revela sub especie contrario en la era escatológica a los miembros de la comunidad.

La cristología de Marcos no se explica en relación con la mesianología en sí misma sino en relación al contexto escatológico en el cual se desarrolla, y que está

\footnotetext{
${ }^{1}$ Todas las citas bíblicas están tomadas del programa Bibleworks.

${ }^{2}$ Weihs, Die Deutung des Todes Jesu im Markusevangelium. Eine exegetische Studie zu den leidens-und Auferheungsansagen, 495.

${ }^{3}$ Carbullanca, "La ignorancia en el Evangelio de Marcos. Un acercamiento desde la literatura de Qumrán a la teoría de las parábolas", 331-358. Allí explicábamos los textos de (1QMyst) fr.1 col I, 2; 4Q266, 5-6 fr. 2 col. I, 5-6; 1QpHab col. VII, 1; 4Q402 fr. 4 14; en el targum Neofiti TNeoGn 24, 15; $\mathrm{Nm} 22,5 ; 24,17 ; 1$ En 1,2 demuestran el origen apocalíptico de la llamada inversión escatológica. Con base en estos textos explicamos que tal inversión representa una "situación epistemológica" acaecida en los últimos días, por causa del pecado de los ángeles caídos, convicción compartida en diversos grupos del judaísmo tardío. Esta falta de entendimiento y rechazo de la voluntad de Dios refleja la situación de caída en que se encuentra la creación y es a la vez un signo escatológico, que muestra el carácter paradójico de la revelación del juicio de Dios. La llegada del Reino de Dios revela la incomprensión en que camina el pueblo lo que impide reconocer el sentido de los hechos acaecidos en los últimos días, en cambio dicho reconocimiento acontece como una revelación dada por Dios a los elegidos.
} 
presente en ambas partes del Evangelio. Como sostiene correctamente Aune (2016), la pretensión de que un futuro salvador no es parte del pensamiento escatológico judío significa que el judaísmo puso el énfasis en la actividad de Dios, más que en el agente elegido, por medio del cual Dios realizaría su plan .

De esta manera, expondremos que el Evangelio de Marcos articula la inversión escatológica y la cuestión mesiánica de manera radical. La primera parte del Evangelio está construida a partir de la convicción del arribo del eschaton $(1,14)$, lo cual se expresa en una epistemología desarrollada en grupos apocalípticos que Marcos asume y elabora de manera radical al expresar que la incomprensión de los misterios del Reino alcanza a los discípulos y al mismo Jesús.

A continuación, en coherencia con esta convicción del arribo del eschaton, el artículo expone la epistemología de la cruz empleada en la segunda parte del Evangelio a partir de tradiciones martiriales.

En ambas partes hacemos evidente que el evangelista expone su cristología en un contexto del arribo del eschaton, pero radicalizando la escatología judía a partir de la figura de la pasión del Justo.

\section{El secreto mesiánico}

La tesis de Wrede (1901) sostiene que el secreto mesiánico es un producto literario del evangelista Marcos, que formula la fe dogmática de la comunidad pospascual. Diversos autores continúan con la posición de Wrede: H. Conzelmann, Ph. Vielhauer y J. Gnilka5. Así, por ejemplo, Ph. Vielhauer afirma que la "idea del secreto ha sido impuesta, pues, artificialmente al texto"6. Y aunque J. Gnilka afirma que la teoría del secreto "es más que un fenómeno puramente literario", sostiene que en "todas las palabras que se atribuyen a Jesús habla aquel que está presente ahora en la comunidad". En esta posición, el secreto mesiánico expresado bajo la cruz $(15,39)$ se comprende como una corrección a una teología de la gloria.

Una variante de esta posición la representa J. Schreiber $(1961)^{10}$, para quien el secreto mesiánico es producto de la fusión del mito gnóstico con el kerigma helenista.

${ }^{4}$ Aune, “The Problem of the Messianic Secret", 19.

${ }^{5}$ Gnilka, Teología del Nuevo Teestamento, 166; Vielhauer, Historia de la literatura cristiana primitiva, 360; Conzelmann, Grundriss der Theologie des Neuen Testaments, 149-151.

${ }^{6}$ Vielhauer, Historia de la literatura cristiana primitiva, 361.

${ }^{7}$ Gnilka, El Evangelio de Marcos I, 195-198.

${ }^{8}$ Ibíd. I, 196.

${ }^{9}$ Conzelmann, Grundriss der Theologie des Neuen Testaments, 151.

${ }^{10}$ Schreiber, "Die Christologie des Markusevangelium”, 159. 
Para este autor, la "teología de la cruz" se explica por dicha fusión, que se opone a una "teología judeo-cristiana" ${ }^{11}$. Para L. Keck sería una reacción a una cristología del theios aner'2 ; para Schreiber ${ }^{13}$, esta teología pretende oponerse a una falsa teología, una cristología del "hijo de David", y se trataría de un "entusiasmo psíquico" ${ }^{14}$ que no guarda relación con el secreto mesiánico.

Para el evangelista, el kerigma helenista está condicionado por este secreto, el cual estaría diseñado según Flp 2,6-11 y 1Co 2,8, donde ve al Salvador de un modo oculto, como un hombre sobre la tierra, por lo cual no será reconocido por los poderes y será luego crucificado. En definitiva, el evangelista pretende historiar el mito de Cristo debido a que postula el valor teológico de la historia de Jesús de Nazaret.

Una segunda posición está representada por autores como E. Schweitzer, N. Perrin, E. Sjöberg, J. Dunn y D. Aune, quienes pretenden sostener que el motivo del secreto mesiánico se retrotrae a tradiciones presinópticas y a la historia del ministerio de Jesús.

Así, por ejemplo, E. Schweitzer $(1965 ; 1970)$ define el secreto mesiánico como "la fundamental oscuridad de Dios [...] que puede ser creído y entendido solo en el discipulado" ${ }^{15}$; para este autor se trata de una comprensión de la revelación de Dios: este es esencialmente un Dios absconditus sub contrario, por lo cual señala que "esta fundamental oscuridad de Dios, la cual es revelada solo a los discípulos, es la que se entiende por secreto mesiánico de Marcos".

N. Perrin (1974) sostiene que este Evangelio fue escrito para el "cristianismo sectario de tipo apocalíptico"16, y afirma que la teología crucis sirve para corregir una teología deficiente que se presenta sobre todo en la segunda sección del Evangelio: "...en la cual Marcos presenta su theologia crucis" ${ }^{17}$.

Por su parte, E. Sjöber -ya en 1955- afirma que Marcos toma de la apocalíptica judía el motivo del secreto mesiánico, según la cual el nombre del Hijo del Hombre estaría oculto ${ }^{18}$. Este intento, a juicio de Schweitzer, es "uno de los más comprensivos intentos de ubicar [el secreto mesiánico] en su contexto histórico". ${ }^{19}$

\footnotetext{
${ }^{11}$ Ibíd., 177.

${ }^{12}$ Keck, "Mark 3:7-12 and Mark's Christology”, 350-351.

${ }^{13}$ Schreiber, "Die Christologie des Markusevangelium”, 159.

${ }^{14}$ Ibíd.

15 Schweitzer, “Mark's Theological Achievement”, 80.

${ }^{16}$ Perrin y Dulling, The New Testament. An Introduction, 256.

${ }^{17}$ Perrin, "The Christology of Mark. A Study in Methodology”, 179; Schreiber, "Die Christologie des Markusevangelium”, 159.

${ }^{18}$ Schweizer, "Zur Frage des Messiasgeheimnisses bei Markus", 1.

${ }^{19}$ Aune, "The Problem of the Messianic Secret", 1-31.
} 
Entre las posiciones críticas a una teoría del secreto mesiánico se pueden contar las de R. J. Dunn (1970) y R. France (2002) ${ }^{20}$. El primero argumenta que, más que hablar de secreto mesiánico, debería hablarse de "malentendidos mesiánicos" 21 o de "misterio del Hijo de Dios" 22 . Para Dunn, el carácter mesiánico del ministerio de Jesús no es el "resultado de una redacción de Marcos, o de una premarcana pero posresurreccional teología cristiana [...] el secreto mesiánico tuvo un origen más bien histórico que teológico". ${ }^{23}$ Un avance en la discusión realizada a partir del trabajo de Sjöber fue la distinción entre estratos de la tradición, así, por ejemplo: “...la incomprensión de los discípulos ante los milagros mesiánicos de Jesús es -según nuestros resultados- no una teoría creada por Marcos, sino un elemento encontrado en la tradición" ${ }^{24}$.

Posteriormente, múltiples autores -como E. Schweitzer, U. Luz, J. Roloff, L. Goppelt y R. Pesch ${ }^{25}$ - harán una diferenciación entre estrato marcano y premarcano de la tradición. Así, para Schweitzer (1965), pertenecen a la tradición premarcana los siguientes eventos: Jesús manda que los demonios se mantengan en silencio; sanaciones en lugares aislados; quizás el silencio de estos enfermos hasta después de que ellos fueran certificados por el sumo sacerdote y la idea de las parábolas necesitadas de interpretación.

Roloff (1969) afirma que el mandato de silencio a los demonios, el misterio vinculado a las sanaciones y el mandato de silencio a los discípulos pertenecen ya a la tradición premarcana ${ }^{26}$.

Goppelt enumera cuatro estratos de esta tradición ${ }^{27}$ : el más antiguo es el secreto mesiánico como elemento estructural de la actuación de histórica de Jesús; este elemento estructural será expresado textualmente en Mc 4,11 y Mt 11,25. Desde tal tradición, Marcos desarrolla el siguiente esquema: la revelación del mesianismo de Jesús a los discípulos con el mandato de silencio y malos entendidos hasta su glorificación; y con ayuda de este esquema Marcos forma su género Evangelio.

\footnotetext{
${ }^{20}$ France, The Gospel of Mark. A Commentary on the Greek Text, 32.

${ }^{21}$ Dunn, "The Messianic Secret in Mark", 100.

${ }_{22}^{2}$ Segalla, La cristología del Nuovo Testamento, 106.

${ }^{23}$ Dunn, "The Messianic Secret in Mark”, 110.

${ }^{24}$ Sjöberg, Der Verborgene Menschensohn in den Evangelien, 163.

${ }^{25}$ Conzelmann, Grundriss der Theologie des Neuen Testaments, 144-145; Schweizer, "Zur Frage des Messiasgeheimnisses bei Markus”, 1; Luz, "Das Geheimnismotiv und die Markinische Christologie”, 9-30; Goppelt, Theologie des Neuen Testaments, 220; Pesch, Das Markusevangelium I, 135-136.245.

${ }^{26}$ Roloff, "Das Markusevangelium als Geschichtsdarstellung”, 84.

${ }^{27}$ Goppelt, Theologie des Neuen Testaments, 225.
} 
Pesch (1977), a su vez, sostiene, siguiendo a Räisänke, un mandato de silencio a los demonios; un mandato de silencio en la historia de las sanaciones, y diferenciará la teoría de las parábolas, la incomprensión de los discípulos del secreto mesiánico, así como la existencia de un relato premarcano de la pasión ${ }^{28}$, que estaría determinado por una teología de la pasión del Justo. ${ }^{29}$ Sin embargo, Marcos no habría acuñado ningún título cristológico propio para expresar su cristología. Además, tanto J. Marcus como R. Pesch unen esta última tradición con tradiciones de origen apocalíptico ${ }^{30}$.

No obstante, R. Pesch sostiene: "Marcos no tiene ninguna concepción cristológica; la cristología de su Evangelio está esencialmente determinada por la cristología de su tradición" ${ }^{31}$, y por tanto no hay una cristología marcana específica, por lo cual rechaza la existencia de la construcción teológica llamada secreto mesiánico, que sería la concepción cristológica a cargo del evangelista; por tanto, el Evangelio no tiene que ver con una unión entre el kerigma helenista y la tradición palestinense, ni tiene que ver con la lucha entre una determinada teología de la gloria y una teología crucis.

Una cuestión importante anotada por Schweitzer (1965) es la radicalización de Marcos respecto de la epistemología apocalíptica: “...la indisponibilidad de Dios es también más radicalmente entendida que en los paralelos. También para los iniciados, los elegidos, permanece Dios indisponible”. ${ }^{32}$ L. Goppelt (1976) entiende también esta radicalización como un desarrollo teológico al sostener que "con ayuda desde una antigua tradición sobre 'el misterio del reino de Dios' es desarrollado teológicamente" 33 . Posteriormente, Weihs (2005) afirmará de manera parecida esta radicalización de la cristología marcana ${ }^{34}$.

\section{El problema mesiánico}

A este panorama debemos añadir que la investigación sobre mesianismo y la cuestión de un mesías sufriente en el periodo precristiano ha cambiado. Hoy, gracias a los estudios de Qumrán, no es raro hablar de una escatología sin mesías, de un doble mesianismo,

\footnotetext{
${ }^{28}$ Pesch, L'evangelo, 72-76; ídem, Das Markusevangelium II, 39. Pesch, afirma como premarcano de 3,$12 ; 8,30$ y 9,9 .

${ }^{29}$ Ibíd., I, 79.

${ }^{30}$ Ibíd., 539.

${ }^{31}$ Ibíd., II, 43.

32 Schweizer, "Zur frage", 3.

${ }^{33}$ Goppelt, Theologie des Neuen Testaments, 222

${ }^{34}$ Weihs, Die Deutung des Todes Jesu im Markusevangelium, 495.
} 
un mesianismo sacerdotal, un mesianismo angelomórfico, o de una concepción popular de mesías ${ }^{35}$, etc. Por tanto, se tiende a descartar la existencia de un canon mesiánico, de manera que diversos autores asumen la opinión de J. Charlesworth (2010), quien sostiene que "los judíos no profesaron una mesianología coherente y normativa" ${ }^{6}$.

En la misma perspectiva se sitúa también N.A. Dahl: “...los textos de Qumrán han mostrado que las doctrinas mesiánica judías fueron abiertas a una gran variedad de lo que anteriormente se había asumido" ${ }^{37}$; y "en el tiempo de Jesús no existió una doctrina normativa del mesías" 38 . De Jonge señala: “...la expectación de un futuro salvador no es parte integral del pensamiento escatológico judío" ${ }^{39}$. Y Aune añade: “...los textos de Qumrán han ampliado considerablemente la cantidad de evidencia literaria de creencias mesiánicas judías del siglo primero d. C.” ${ }^{40}$. Jonge llega a dos aspectos fundamentales:

- Durante el primer siglo, la cuestión mesiánica es un aspecto secundario relegado a la cuestión fundamental del arribo del eschaton.

- Las figuras con una pretensión mesiánica se amplían drásticamente a partir de estas investigaciones ${ }^{41}$.

También Aune y Dunn ${ }^{42}$ concluyen que es preferible hablar de "creencias mesiánicas judías" o de "ideas mesiánicas". $\mathrm{Al}$ asumir estos antecedentes, es preciso atender de manera especial la creencia en un profeta-mesías.

Comprobamos primero que las creencias mesiánicas en un "profeta-mesías" vinculado a la revelación de secretos en los últimos tiempos fueron apropiadas por líderes carismáticos en el cambio de era. Ejemplo de ello son los textos de 11QMelq y 1 QHa (siglo I a. C.): ambos utilizan Is 61,1-2. En relación con 1QHa, col. XXIII, fr. 1 , en el cual Is 61,1 ss. es apropiado por el Maestro de Justicia, de manera similar a lo que hace Jesús posteriormente (Lc 4,18): “...un heraldo (מבשר) de tu bondad, para proclamar a los pobres la abundancia de tu compasión [...] de una fuente [...] a los

${ }^{35}$ Dunn, "The Messianic Secret in Mark", 110; Aune, "The Problem of the Messianic Secret”, 1-21.

${ }^{36}$ Charlesworth, From Messianology to Christology, 35

${ }^{37}$ Dahl, "Messianic Ideas”, 17-381.

${ }^{38}$ Ibíd., 389; Longenecker, “The Messianic secret”, 213-214.

${ }^{39}$ De Jonge, "The Use of the Word 'Anointed', 133-134.

${ }^{40}$ Aune, "The Problem of the Messianic Secret", 17.

${ }^{41}$ Las objeciones de M. Hengel y D. Juel respecto de la figura de un mesías mártir nos parecen erradas Hengel, Atonement, 41; y Juel, Messianic Exegesis, 103.

${ }^{42}$ Aune, "The Problem of the Messianic Secret", 17; Dunn, "Messianic Ideas", 17-381 
de espíritu quebrantado, y a los que están de duelo eterna alegría"; también ocurre la identificación de Juan el Bautista con el Elías redivivus (Mc 9,13; Lc 7,21).

Por otra parte, está suficientemente acreditada en fuentes apocalípticas y en Qumrán la creencia en un mesías profético semejante a Elías o Moisés. Por ejemplo, en 4Q521,1 (39 a. C y 66 d. C.): "los cielos y la tierra escucharán a su mesías (למשיהו)"; ello alude al Sal 146 que, en los vv. 7-9 menciona una lista de personajes semejante a la encontrada en Is 61,1 y 35,5, pero en el texto masorético el salmo está referido a la persona de Yahveh; en cambio, en 4Q521 está referido al mesías. En otro texto, 4Q377, aparece la idea mesiánica de Moisés escatológico visto como un ser trascendente (4Q377, fr. 1, recto col. II, 5-12); específicamente, en el v. 5 de este texto, Moisés es "su mesías" (מושה משיחו) y en el v. 10 es "el hombre de Dios" (מלאך) (מלשך) y "énangelizador" (מבשר).

En segundo lugar, si atendemos a los Himnos (1QHa), probablemente escritos por el mismo Maestro de Justicia, encontraremos que el narrador habla en primera persona y señala que Dios ha dado a él su espíritu (Col. XX, 12; col. IV, 26; 4Q427 fr.2, 12). Este aspecto no es menor, pues un elemento central de la cristología de Marcos son los textos de Mc 1,11, 9,7, 12,6 y 15,36, en los cuales el Hijo amado es portador del Espíritu divino de acuerdo con el texto de Is 42,1. Esto refleja que probablemente los miembros de la comunidad consideraron al Maestro de Justicia como el profeta de los últimos tiempos. En 11QMelq, v. 20, se cita el texto de Is 61,1 -que es mencionado en los primeros textos neotestamentarios-, y aquí interpreta al evangelizador (מבשר) (Is 52,7) con el profeta escatológico: "Y el mensajero de buenas noticias que anuncia la salvación es uno sobre quien está escrito que [...] (Is 61,2) 'consolará a los afligidos' su interpretación para que ellos sean instruidos en todas las edades del mundo".

Vinculado al segundo aspecto está el hecho de la enseñanza o interpretación carismática que desarrolla este mediador. Podemos apreciar que la doctrina de un mediador trascendente quien revela los misterios divinos a la comunidad de los últimos tiempos, la encontramos en la primera apocalíptica a Enoch: “...hubo un hombre cuyos ojos fueron abiertos por Dios [...] visiones que no son para esta generación, sino para una lejana que ha de venir" (1Enoch 1,2). Como al Hijo del Hombre -en las Parábolas de Enoch- Dios "revelará todos los tesoros de lo oculto" $(47,3)$, también en 1QpHa, col. VII,1, el Maestro de Justicia enseña e interpreta escatológicamente las palabras de los profetas.

Además, tanto 1Enoch como las Parábolas de Enoch comparten la doctrina sobre secretos escatológicos; y este último solo continúa la perspectiva escatológica al señalar que el nombre del Hijo del Hombre "fue mencionado antes de crear las 
estrellas de los cielos ante el cabeza de Días" $(46,3)$ y también que su nombre (del Hijo del Hombre) será revelado en los últimos días $(69,26)$.

Un tercer aspecto importante del libro de las Parábolas de Enoch ${ }^{43}$-además de los títulos expresados del Hijo del Hombre, como "el Elegido", "el Ungido", "el Justo", etc.- consiste en que los diversos personajes -Enoch, Abel o el Hijo del Hombre- realizan funciones escatológicas como son las de "atar a Azazel", proclamar el "Yom Quippur escatológico" y declarar la paz a los elegidos (Enoch 1,19; 11QMelq col II.7; 4Q541; Ml 4,5-6). Y en diversos textos se introduce la cuestión de un mediador celeste que realiza funciones escatológicas enviado por Dios. Por ejemplo, en estos textos, la expiación escatológica es una función mesiánica realizada por un mediador celeste; así lo podemos ver en 11Melq, col. II.7: Melquisedec realiza la liberación anunciada en Is 61,1 en el día del Yom Quippur escatológico.

Estos antecedentes muestran que las ideas mesiánicas en diversas partes de la Palestina del siglo I a. C. consideraban figuras proféticas variadas que realizaban funciones escatológicas, de la manera como las encontramos asumidas y elaboradas en el Evangelio de Marcos bajo la idea de una economía de la cruz.

La breve panorámica que hemos presentado sobre la cuestión mesiánica objeta las antiguas polémicas en torno del tema mesiánico en el Evangelio de Marcos y abre su estudio a nuevas síntesis que toman en cuenta los últimos estudios sobre el judaísmo tardío y, sobre todo, la mesianología en Qumrán, que muestran la necesidad de situar históricamente la cuestión mesiánica y el sentido que pudo tener la muerte de Cristo en este contexto.

\section{Mesianismo e inversión escatológica}

\section{Escatología y secreto mesiánico}

El Evangelio de Marcos fue escrito alrededor de los años 70 d. C., bajo la convicción de estar viviendo los últimos tiempos $(1,14 ; 9,1 ; 4,11)$. Esta convicción está aún presente en la época del evangelista y se aprecia claramente en las tradiciones que él reelabora. La primera parte, que muestra al mesías incognitus, está construido en el esquema marcano de la epistemología de la cruz, la cual responde a la mencionada inversión escatológica ${ }^{44}$.

${ }^{43}$ Black, "The Messianism of the Parables of Enoch", 162; Nickelsburg, Jewish Literature, 221-223

${ }^{44}$ Schweizer, Zur Frage, 13; Carbullanca, "La ignorancia en el Evangelio de Marcos”, 331-358. 


\section{La inversión epistemológica, el reino sub specie contrario}

La inversión epistemológica se expresa a través del Evangelio, por una parte, en una serie de pasajes: la predicación de Jesús es incomprensible para "los de fuera" (Mc 4,11-12); los ciegos que han recuperado la vista $(8,22 ; 10,46-51)$; incluso el texto de Mc 9,1 muestra una errada espera de Jesús sobre el final de los tiempos y la hora del juicio (Mc 13,32).

Por otra parte, el evangelista elabora algunos temas literarios, como la incomprensión de los discípulos en relación con el misterio de Jesús. Si esta inversión está ya presente en los materiales producidos por el evangelista, entonces tiene razón E. Sjöber al afirmar que el secreto mesiánico no es un argumento dogmático, ni solo un anuncio kerigmático, sino "un esencial elemento de la cristología del Evangelio, necesario para la relación orgánica de esta”"45.

En el logion de Mc 13,32, se muestra que la hora del juicio es desconocida; esto es, la inversión escatológica, la ignorancia de la hora es un principio que alcanza incluso al mismo Jesús ${ }^{46}$. Como ya hemos señalado, en Qumrán encontramos -en los Cánticos del sacrificio sabático (4Q402 fr. 4 14) - una convicción similar, según la cual incluso los ángeles ignoran los secretos de Dios. Y en Mc 4,11-12 se señala que la predicación de Jesús revela una situación epistemológica: los de afuera están ciegos, no comprenden las parábolas, de la manera como lo señala el profeta Isaías: tanto el reconocimiento de la persona y mensaje del Reino es un regalo de Dios, y como E. Schweitzer lo afirma correctamente: "solo Dios mismo puede revelar el significado de las parábolas" ${ }^{47}$.

\section{Los textos de Mc 4, 11-34; 13, 32 y 14, 64}

Pesch sostiene, siguiendo a Räisänen, que es necesario diferenciar entre secreto mesiánico y teoría de las parábolas: “...claramente se diferencia el secreto mesiánico de la teoría de las parábolas, v. 4,11ss., permanece para Marcos como un cuerpo extraño" ${ }^{38}$. Esta teoría de las parábolas ha servido, según Pesch, como el mejor argumento para defender el carácter apologético del secreto mesiánico. En efecto, existen diferencias entre el secreto mesiánico y la teoría de las parábolas, y la identidad del mesías se produce en el contexto de la inversión escatológica ${ }^{49}$.

\footnotetext{
${ }^{45}$ Sjöberg, Der Verborgene Menschensohn, 132.

${ }^{46}$ Carbullanca, "La ignorancia en el Evangelio de Marcos", 331-358.

${ }^{47}$ Schweizer "Die theologische Leistung des Mark”, 21-24; ídem, "Zur Frage”, 11-20.

${ }^{48}$ Pesch, Das Markusevangelium II/2, 38.

${ }^{49}$ Carbullanca, "La ignorancia en el Evangelio de Marcos”, 346.
} 
El texto de Mc 4,11-34 recoge tradiciones anteriores al evangelista, quien las agrupa y otorga al Evangelio una clave de comprensión general, a saber, los vv. 11-12. Para U. Luz, el v. 11 no pertenece al evangelista: "Marcos no emplea nunca redaccionalmente la expresión Reino de Dios, sino que pertenece a la tradición”. ${ }^{50}$

En el logion del versículo 11, el evangelista Marcos asume una perspectiva apocalíptica y muestra que la inversión escatológica ha sido adoptada por él para indicar la situación escatológica en la que se encuentran los oyentes de las parábolas ${ }^{51}$ (Mt 13,11-17). Esto también se advierte en el material apocalíptico de Mc 13,1-37: en los vv. 32-33, en consonancia con 4Q402, fr.4 14 -"pero de aquel día y de la hora nadie sabe, ni aun los ángeles que están en el cielo, ni el Hijo, sino el Padre”- se aplica dicha inversión epistemológica, tanto a los ángeles como al Hijo.

En los escritos apocalípticos, la oscuridad e incomprensión escatológica es un misterio referido a los últimos días que es revelado a los elegidos y que en el Evangelio alcanza al mismo Jesús y a sus discípulos. Este dato es importante, pues muestra que la radicalización de la inversión epistemológica, en el Evangelio de Marcos, consiste en una novedad cristiana.

De manera diferente a los esenios, Marcos pretendió decir que la situación epistemológica acerca de la hora era un misterio que alcanzaba a los discípulos y a la persona de Jesús. Si la inversión escatológica apuntaba a describir el plan salvífico de Dios en los últimos días, el evangelista ha radicalizado y extendido esta descripción a la persona de Jesús, tanto por medio de los dichos sobre el Hijo de Hombre como por los referidos al Hijo.

Esta radicalización revela la situación de oscuridad en que se encuentra el cosmos, semejante a la que expresa Jn 8,12. Lo mismo ocurre en el logión apocalíptico de Mc 14,62, que presupone la convicción de que los enemigos de Jesús no lo reconocen en su condición humilde como el Hijo del Hombre anunciado por Dn 7,13. En este dicho apocalíptico, sin embargo, hay un hecho notable, pues la inversión epistemológica funciona normalmente en contra de los impíos, quienes no conocen, ni ven, ni oyen. En cambio, en este logion, la inversión es radicalizada al aplicarla a los mismos enemigos de Jesús: “...Y veréis al Hijo del Hombre sentado a la diestra del poder de Dios y viniendo en las nubes del cielo". El texto de Dn 7,13 es interpretado escatológicamente, según lo cual los beneficiados por la revelación son los mismos jueces de Jesús; esto se explica porque en algunas corrientes apocalípticas

${ }^{50}$ Luz, "Basileia”, 607-608.

${ }^{51}$ Sjöberg, Der Verborgene Menschensohn, 124-125. 
-como la enóquicas- se pensaba que la revelación acaecida con la venida de Yahveh sería un acontecimiento patente a todos, impíos y elegidos.

\section{Endurecimiento como un misterio}

La cita de Is 6,9, en Mc 4,12, es una interpretación escatológica del v. 11, la cual desde un análisis del lenguaje es una sucesión de negaciones: "teniendo ojos y no ven, teniendo oídos y no oyen", "no entender", "no saber", "cómo entenderéis"... Todas ellas pertenecen a un mismo campo semántico que relaciona verbos el tema de la inversión epistemológica con la idea del endurecimiento de Israel, la cual es la raíz de la incomprensión tanto del pueblo como la de los discípulos ${ }^{52}$. Esto queda claramente expresado en Mc 8,17: "Jesús, les dijo: '¿Qué discutís? ¿Por qué no tenéis pan? ¿No entendéis ni comprendéis? ¿Aún tenéis endurecido $\left(\pi \varepsilon \pi \omega \rho \omega \mu \varepsilon^{2} \nu \eta \nu\right)$ vuestro corazón?’”.

Este texto es importante, ya que relaciona la incomprensión de los discípulos y la ceguera del pueblo con el tema el pecado del endurecimiento del corazón que ambos grupos comparten ante la presencia misteriosa del Reino $(8,33 ; 6,52 ; 7,18$; $8,17-21)$. Ello muestra que no es un predeterminismo lo que suscita la ceguera y el endurecimiento sino es el pecado de corazón endurecido que no quiere ver ni oír, como lo señala Is 6,9 .

Se puede comprobar que la utilización del texto de Is 6,9 en los primeros tiempos del cristianismo tuvo relación con la incomprensión y el fracaso en la predicación de los profetas enviados a Israel, y también con la predicación del Reino de manera que este fue considerado un misterio ( $\mathrm{Rm} 11,25$; Mc 3,5). La interpretación paulina del texto de Rm 11,25 ("no quiero que ignoréis este misterio: que ha acontecido a Israel endurecimiento en parte, hasta que haya entrado la plenitud de los gentiles") expresa el endurecimiento de Israel es un misterio que origina la incomprensión de la presencia del Reino; además, la cantidad de veces en que es citado el texto de Is 6,9 en los textos del primitivo cristianismo muestra la importancia de este tema en ese tiempo $^{53}$ (Hch 28,26ss.; Jn 12,37-41, o es aludido como en Rm 11,8.10).

\footnotetext{
${ }^{52}$ Gnilka, Verstockung, 32.39; Los textos de CD A II, 18=4Q266 fr. 2 col. I, 18: "por haber marchado en la obstinación de sus corazones cayeron los vigilantes de los cielos”. Este texto recoge un tema mítico, y coloca como la dureza de corazón el pecado de vigilantes del cielo. El texto continúa contraponiendo que ni Abraham, ni Isaac ni Jacob caminaron en ese camino de obstinación. El endurecimiento de Israel se relaciona con el tema de la ceguera: es Dios quien cierra los ojos, y provoca la ceguera de los impíos, en CD I, 10; XVI, 2-4; 1QS IV, 1. La ceguera no es una característica física sino un concepto hermenéutico fundamental que refleja la última etapa de la historia. Así como la ceguera e incomprensión de los discípulos y dirigentes judíos en Marcos. es signo del fin (ver CD II, 17; III, 5. 11; VIII, 8. 19; XIX, 20. 33; XX, 9; 1QS II, 14. 25; III, 3; V, 4; VII, 19. 24; IX, 10; 4Q266; 1QHa col. II, 21).
}

${ }^{53}$ Haufe, “Erwägungen”, 418-419. 
Por tanto, es posible que el logion de 4,11-12 refleje una antigua tradición apocalíptica y cristiana que entendió la incomprensión y el rechazo del mensaje del Reino a la luz de los textos de Is 6,9, Jr 5,21 y Ez 12,2. Ellos hablan del fracaso que sufren los profetas, por el pueblo de Dios, por causa del endurecimiento del corazón del pueblo judío. Sin embargo, esta misma incomprensión y rechazo son un signo profético de la llegada del Reino de Dios; es decir, revelan una situación escatológica: no solo indican la mala disposición del pueblo ante la predicación de Jesús sino también revelan el carácter escatológico de la historia y del pueblo judío ante el Reino.

\section{Los relatos de exorcismos y el motivo del Justo}

En la fundamentación de la teoría del secreto mesiánico, en la argumentación de Wrede, los relatos de exorcismos estaban en primer lugar. Los estudios realizados sobre judaísmo y Qumrán muestran, en el análisis de la escena de los exorcismos, un claro carácter ideológico. Dos de ellos -1,23ss. y 5,7- a juicio de Jünger Roloff, son premarcanos ${ }^{54}$. Con ello se comprueba que, en uno y en otro, las confesiones de los demonios y el mandato de silencio -en 1,24ss.- son un componente de un tópico tradicional que vincula los exorcismos con la figura del Justo, como lo demuestran diversos textos apocalípticos (Test Salomón 6,11).

En ellos, el Justo es un mesías y un exorcista que lucha e intercede por el pueblo contra los demonios, según lo cual los justos no solo padecen sino que luchan y colaboran -como los ángeles- contra los demonios ${ }^{55}$. En estos relatos resuenan representaciones mitológicas apocalípticas. En el Evangelio de Marcos, Jesús se presenta en lucha con los espíritus cósmicos, que por medio del empleo del nombre del demonio o de Jesús buscan obtener poder sobre el adversario. En los sumarios de 1,34 y 3,11 ss., este tópico está evidentemente comprobado. Marcos no indica "que los demonios han comprendido mal a Jesús, sino muestra que ellos conocen desde un comienzo de su dignidad secreta". ${ }^{56}$

La conclusión de Roloff es correcta: “...se confirma el juicio que mandatos de silencio a los demonios son redaccionales y una tradición dada que ha sido ampliada, sin que por esto cambie fundamentalmente" ${ }^{\text {57 }}$. Esto, porque en las tradiciones apocalípticas

\footnotetext{
${ }^{54}$ Roloff, "Das Markusevangelium als Geschichtsdarstellung”, 85.

${ }^{55}$ Carbullanca, "Demonología", 211-233.

${ }^{56}$ Roloff, "Das Markusevangelium als Geschichtsdarstellung”, 84.

${ }^{57}$ Ibíd., 84.
} 
vinculadas al esenismo, primero ángeles, y luego, los patriarcas y profetas, colaboran con Dios en la lucha contra los demonios en un combate con caracteres escatológicos.

Como lo señalamos en nuestro estudio, la misión del Hijo del Hombre enóquico y las bendiciones de los patriarcas en Jubileos (175-100 a. C.) están vinculadas a la función escatológica de "atar a Azazel" o "atar al fuerte", en el Test XII Patriarcas (1Enoch 10,4; 69,28; Jub10, 5-7; 23, 29; 50, 5; TestLevi 18,1 y Mc 3,22). A diferencia de los justos presentes en el salterio, que exclusivamente padecen la injusticia de los impíos, encontramos en textos apocalípticos como 11Q11, col. II, 1, v. 2, el nombre de Solomón, un mesías, como exorcista, quien dice: "él invocará", en el vv. 3-4 (... los espíritus y los demonios...); también se encuentra en el TestJob 27,1-7 y en TestSalomón 6,11, donde el Justo es un "atleta" que lucha contra Satán.

Los motivos de la función escatológica del Justo contra los demonios se repiten en los relatos de exorcismos, como Mc 1,21-28 y 3,11-15: "Designó entonces a doce para que estuvieran con él, para enviarlos a predicar y que tuvieran autoridad para sanar enfermedades y para echar fuera demonios". Si la lucha escatológica de Jesús contra los demonios se identifica con el arribo del Reino escatológico, se la inscribe como un motivo central del Evangelio, en el cual el reconocimiento de la identidad de Jesús por parte de los demonios $(1,24 ; 5,7)$ está inserto desde un comienzo y responde a la epistemología apocalíptica según la cual la identidad angelomórfica del Hijo del Hombre es reconocida en los cielos; en cambio, en el ámbito terreno los hombres están cegados y no reconocen el arribo del Reino y la verdadera identidad de Jesús, lo que establece una relación próxima con la epistemología presente en Mc 4,11.

Esta convivencia entre la lucha escatológica de los justos contra los demonios y el reconocimiento de la identidad del Hijo del Hombre no son dos motivos separados, ni el segundo es causado por la redacción marcana, sino pertenecen ya a la tradición.

\section{Cristología y muerte de Cristo}

La pasión y muerte del Hijo del Hombre aparece en la segunda parte del Evangelio de acuerdo con la ya mencionada inversión escatológica en Mc 8,32-33: "Y claramente decía esta palabra. [...] Apártate de mí, Satanás; porque no sabes las cosas que son de Dios, sino las que son de los hombres"; y en Mc 9,32: "Pero ellos no entendian esta palabra, y tenían miedo de preguntarle"; y en Mc 10,38: “...entonces Jesús les dijo: No sabéis lo que pedís”.

A pesar de que la Palabra es presentada "claramente", los discípulos "no entienden", "no saben" la verdadera dimensión de los acontecimientos. Esta incomprensión de los discípulos muestra que el evangelista ha modulado la historia de la pasión de acuerdo con este marco epistemológico. 
Las referencias acerca de la pasión del Hijo del Hombre están desplegadas en la segunda parte del Evangelio, desde la decisión de matarlo en 3,6, 11,18, 12,12ss. y las tres predicciones de la pasión; 8,31, 9,31, 10,32ss., que son acrecentadas por 9, 9.12; 10, 45; 14, 21.18.27.30, y subrayan la importancia de esta estructura para Marcos. Ahora bien, el evangelista ha asumido diversas tradiciones martiriales, las cuales ciertamente eran portadoras de su propia visión cristológica ${ }^{58}$. La integración de este relato muestra que, para el evangelista, las tradiciones martiriales adoptadas por él han sido moduladas de acuerdo con la clave epistemológica que proporcionaba el relato premarcano de la pasión no sin ciertas tensiones.

$\mathrm{Al}$ asumir lo anterior, Marcos desarrolla su cristología fundamentalmente con base en la tradición de la pasión del Justo (persecución-exaltación) ${ }^{59}$ mencionado en el relato premarcano como el Hijo del Hombre ${ }^{60}$; no obstante, existen otras dos tradiciones, en tensión con aquella, conocidas como exhortatio ad martyrium ${ }^{61}$, y otra entendida como sentido expiatorio de la muerte de Cristo ${ }^{62}$.

\section{La tradición apocalíptica de la pasión del Justo}

Para J. Dunn, la tradición de la pasión del Justo representa una "potencial idea mesiánica” ${ }^{63}$ por lo cual debemos atender a ella de manera especial. El relato premarcano de la pasión está determinado por esta tradición ${ }^{64}$ presente en los salmos, los textos proféticos y apócrifos ${ }^{65}$, que expresa un inversión epistemológica en la manera de comprender el estatuto del sufrimiento y muerte del Justo o del mártir. Una característica fundamental de esta consiste en que el sufrimiento del Justo, del Hijo del Hombre, es entendido como un medio necesario para realizar el misterioso plan de Dios en la historia (Sab 2,4-5,7; Enoch 102-104) . $^{66}$.

\footnotetext{
${ }^{58}$ Marcus, "Mark 4:10-12 and Marcan Epistemology", 572.

59 Weihs, Die Deutung des Todes Jesu im Markusevangelium, 495; Gübler, Die Frühesten deutungen des Todes Jesu, 95-205; Baumester, Die Anfänge der Theologie des Martyriums, 68-76; Theissen, $A$ Theory of Primitive Christian Religion, 139-160.

${ }^{60}$ Pesch, Das Markusevangelium II, 25.

${ }^{61}$ Weihs, Die Deutung des Todes Jesu im Markusevangelium, 207-213; Gübler, Die Frühesten deutungen des Todes Jesu, 206-335; Theissen, A Theory of Primitive Christian Religion, 139-160.

${ }^{62}$ Weihs, Die Deutung des Todes Jesu im Markusevangelium, 499-523; Gübler, Die Frühesten deutungen des Todes Jesu, 206-335; Theissen, A Theory of Primitive Christian Religion, 139-160; Wengst, Christologische Formeln und Lieder des Urchristentums, 71-77.

${ }^{63}$ Dunn, "Messianic Ideas and Their Influence on the Jesus of History", 378.

${ }^{64}$ Pesch, Das Markusevangelium I,79; Penna, I ritratti originali di Gesu il Cristo. Inizi and svilupi della cristologia neotestamentaia, 19-27.

${ }^{65}$ Pesch, L'evangelo della comunitá primitiva, 72-75.

${ }^{66}$ Nickelsburg, Jewish Literature between the Bible and The Misnah, 148.
} 
En el relato de la pasión premarcano se encuentra diseñada la tradición del Justo paciente (Sal 54,5; 37,32; 63,10; 71,10; 86,14; 109,16), el motivo de los testigos falsos (Sal 27,12; 35,11), y el del silencio del Justo frente a la acusación de los adversarios (Sal 28,14-16; 39,10). Las innumerables citas de los Salmos esparcidas por estos capítulos, así como las referencias al Justo (ver a Enoch 38,$2 ; 53,6 ; 71,16$ ) - pero también a Is 53,11 y a Sab 2,12-20; 5,1-7- son recepcionadas en las tres profecías de la pasión, Mc 8,31; 9,11-13 y 10,33. A juicio de diversos autores, estas son usadas para describir que el destino de sufrimiento del Justo - "el Hijo del Hombre debe sufrir mucho", "ser asesinado" y "resucitar". (то $\lambda \lambda \dot{\alpha} \pi \alpha \theta \in \hat{\imath} \nu$ ) $(\dot{\alpha} \pi 0 \kappa \tau \alpha \nu \theta \hat{\eta} \nu \alpha \iota)(\dot{\alpha} \nu \alpha \sigma \tau \hat{\eta} \nu \alpha \iota)(12,5-8 ; 14,1)$ - se realiza de acuerdo al plan de Dios.

En este cuadro presentado por el evangelista, el sufrimiento cambia de estatuto epistemológico: ya no es castigo de Dios, ni una pedagogía divina, sino que posee una función escatológica, para realizar el plan de Dios en la historia. Esta teodicea apocalíptica diseña, mediante el esquema de humillación-exaltación, una respuesta posmortem al problema del sufrimiento, perspectiva ausente tanto en la tradición deuteronomista como en la tradición de la pasión del Justo presente en el salterio. Por tanto, la condición de la salvación escatológica es la participación en el sufrimiento, la persecución y el martirio del Justo.

En el cuadro del Justo que sufre son de particular importancia las llamadas "fórmulas de entrega" ( $\pi \alpha \rho \alpha \delta i ́ \delta \omega \mu \iota)$, que nos proporcionan una clave para comprender la tradición martirial, pues este verbo $(\pi \alpha \rho \alpha \delta i \delta \omega \mu \iota)$ se ocupa en la tradición sinóptica para describir tanto la pasión y muerte de Juan el Bautista como la del Hijo del Hombre (Mc 1,14; 9,31; 10,33 y 14,41). Así pues, vemos que en Mc 1,14 y 9,31 se subraya la "participación activa" de Dios en la entrega de Juan el Bautista y del Hijo del Hombre y la perspectiva escatológica del relato ${ }^{67}$. Las fórmulas sinópticas de "entrega" se enraízan en un amplio medio teológico, determinado por la apocalíptica y el motivo de la "pasión del Justo".

En esta tradición, el estatuto epistemológico del sufrimiento del Justo es clave hermenéutica y crítica fundamental. Los cuatro textos -8,31; 9,31;10, 33 y 14,31-

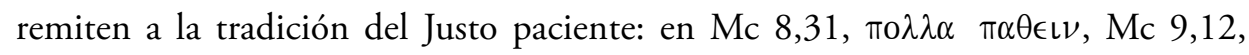
$\pi 0 \lambda \lambda \dot{\alpha} \pi \dot{\alpha} \theta \eta$, son una cita de los salmos del Justo que sufre (Sal 34,10; 40,13; 71,20; 88,4); pero se puede apreciar que esta tradición es superada gracias al esquema apocalíptico del martirio reivindicado al añadir, en Mc 8,31c, "ser muerto, y resucitar después de tres días”; y en relación con Juan Bautista, en Mc 9:13: “...hicieron todo lo que quisieron", que alude a su muerte relatada en 6,17-29.

${ }^{67}$ Keck, “The Introduction to Mark's Gospel”, 360. 
En Mc 10,33 está confirmada la pertenencia a la tradición del Justo por el texto de Qumrán (4Q372, fr. 1, 15): “Ahora subimos a Jerusalén, y el Hijo del Hombre será entregado a los principales sacerdotes y a los escribas ( $\pi \alpha \rho \alpha \delta 0 \theta \eta ́ \eta \epsilon \tau \alpha \iota)$. Lo condenarán

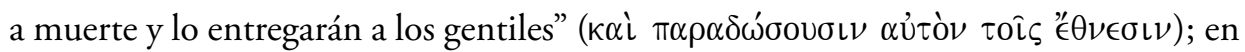
Qumrán, encontramos -en 4Q372, fr.1, 15- la expresión "ser entregado en manos de los extranjeros", aplicado a José como figura del justo paciente; también en el dicho de Mc 14,41 - "he aquí, el Hijo del Hombre es entregado ( $\pi \rho \rho \delta \delta i ́ \delta o \tau \alpha \iota)$ en manos de los pecadores" - tales expresiones se remiten a la pasión del Justo.

La tradición del Justo expresaba, en la primera parte del Evangelio, la función escatológica de la lucha contra los demonios y la de "atar a Azazel" como su motivo central. La primitiva teodicea dualista en la que el Justo lucha contra los demonios es absorbida por la teodicea más elaborada representada por la tradición del Justo a partir de Mc 8,31. Ella expresa la función escatológica según la cual profetas y justos participan con sus sufrimientos en los eventos escatológicos.

La colaboración en la lucha escatológica ya era una característica notoria en la teodicea dualista, como puede apreciarse en los relatos apocalípticos tempranos, y esta función escatológica de colaboración no integraba expresamente "cargar con los dolores y sufrimiento". Posteriormente, encontramos en textos de Qumrán -como los 4Q491c- esta función escatológica: “¿Quién es comparable a mi gloria? [...] ¿Quién lleva todos los sufrimientos como yo? ¿Y quién sufre el mal como yo? No hay ninguno". También en Hoyadot, col. XXIII, 14-15, en los cuales cita a Is 61,1-5: “...de acuerdo a tu verdad, un heraldo [...] de tu bondad para proclamar a los pobres la abundancia de tu compasión [...] de la fuente [...] a los de espíritu quebrantado y a los lloran alegría eterna"; y en diversos pasajes de $1 \mathrm{QHa}$ col X, 10-12; 32-33, que recuerdan los salmos del Justo paciente y las confesiones de Jeremías, donde anuncio y sufrimiento están vinculados en la misma persona del profeta ${ }^{68}$. Esto muestra que ya en tiempos precristianos existió la idea de una función escatológica de los sufrimientos del profeta de los últimos tiempos como colaboración en la lucha escatológica.

Este cambio de estatuto ya previsto en tradiciones judías apocalípticas es radicalizado por Marcos en contraste a la convicción judía del Sal 91 (Lc 4,10-11), según la cual los demonios no triunfan ante el Justo, desmentida en Getsemani en consonancia con tradiciones apocalípticas del Justo. El Evangelio de Marcos relata la derrota y muerte ignominiosa del Hijo del Hombre. Los acontecimientos escatológicos son narrados en continuidad con la apocalíptica judía según la cual el Hijo

\footnotetext{
${ }^{68}$ Carbullanca, “¿Una teología del martirio en 1QHa y 4Q491c? Aportes para la comprensión de la cristología del Hijo del Hombre joánico”, 124.
} 
del Hombre es entregado en manos de los pecadores, expulsado de la viña (12,1-11), entregado en manos de las autoridades $(8,31 ; 9,31)$, condenado por la autoridad civil $(10,33 ; 15,15)$, abandonado por "el cristianismo" (14,17-21.26-25) - "todos lo abandonaron y huyeron" $(14,50)$ - y por su mismo "Dios y Padre".

La muerte del Hijo del Hombre es descrita en términos apocalípticos: acontece en tinieblas (ver Mc 15,33), según una secuencia de horas (15,25.33.34.42; 16,1), con un grito en la cruz. Esta secuencia muestra el interés de situar la historia de la pasión de Jesús de Nazaret en la historia arquetípica de humillación-exaltación sapiencial de los justos que vencieron. En cambio, en la literatura apocalíptica la condición de humillación de los justos comienza a volverse la causa formal para aspirar a una resurrección de los muertos.

El hecho de que Jesús no vence sino de que es derrotado muestra que el evangelista ha querido radicalizar la pasión del Justo existente en los salmos. En esta derrota y abandono del Hijo del Hombre se produce la inversión axiológico-epistemológica: el sufrimiento y muerte por la justicia del Hijo de Dios expresa un cambio escatológico, pues ni el Templo ni sus mediaciones son ya el lugar donde se revela Dios, sino el sufrimiento de los justos, ahora radicalizado en el Hijo de Dios.

\section{Getsemaní como pasión del Justo}

La cuestión cristológica se presenta vinculada a la cuestión del sentido escatológico o moral que tuvo la muerte del Hijo del Hombre. Así, en diversos pasajes del Evangelio de Marcos, en la figura de la entrega del Hijo del Hombre se presenta la duda de si corresponde a una exhortatio ad martyrium o al modelo de la pasión del Justo, por ejemplo, en el dicho de Mc 14,32-42, de 10,37-40, o de 8,34 (Jn 12,26).

Gerd Theissen sostiene que 8,34 está vinculada al motivo del Justo sufriente como una exhortatio ad martyrium ${ }^{6}$. También Pesch, Moss y Theissen sostienen que la tradición del Justo está caracterizada como una disposición al martirio ${ }^{70}$. Lo

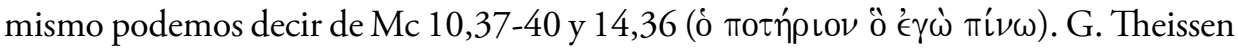
se detiene en la imagen de la copa y presenta dos textos del diálogo de Santiago y Juan con Jesús, en Mc 10,37-40 y en Getsemani 14,36. Según este autor, "la ejecución de Santiago fue interpretada con ayuda de la metáfora de la copa". Al parecer -asegura-, "en los años 40 hubo un grupo que interpretó la muerte de los mártires

\footnotetext{
${ }^{69}$ Theissen, A Theory of Primitive Christian Religion, 29-33; Baumester, Die Anfänge der Theologie des Martyriums, 72-76.

${ }^{70}$ Theissen, The Gospel in Context: Social and Political History in the Synoptic Tradition, 145; Pesch, Das Markusevangelium I, 61.80.
} 
cristianos como 'bebiendo la copa"' ${ }^{71}$, que narraron el relato del temor de Jesús en Getsemani como para hacer del mismo un modelo para todo cristiano que deba enfrentar la muerte.

Ciertamente -como ya hemos visto-, el evangelista elaboró diversas tradiciones martiriales, como la disposición al martirio y la pasión del Justo, en un marco apocalíptico. Podemos ver que Marcos 14,32-42 pretende dejar constancia de momentos en los cuales Jesús se alejó e hizo oración a solas, o enseñó el poder exorcista de la oración; dicha oración se inscribe en el género de oraciones exorcistas, como las que encontramos en tradiciones judías en los cuales ángeles y justos interceden por el pueblo o exorcizan al pueblo en contra de determinados demonios ${ }^{72}$.

La insistencia acerca de la oración "orar para no caer en tentación" (vv. 32.40.46) tiene sus antecedentes, en Si 2,1, y recoge el tema de la pedagogía divina (1P 1,6, 4,12 ) con palabras de Popkes - "un medio empleado por la pedagogía divina" 73 - o con caracteres sapienciales. A juicio de este autor, la tentación responde a "la prueba a menudo dolorosa a que Dios somete al piados (Abraham, Job, etc.); el tema se asocia con el del Justo sufriente y el de la pedagogía sapiencial" ${ }^{4}$.

El tema del peirasmos, también presente en TestJob 27,1-7, muestra al justo Job como un "atleta" que lucha contra Satán. Sin embargo, el tema no está solo vinculado a una preocupación parenética sino que expone el drama cósmico de la lucha escatológica. En efecto, el tema de los demonios y la hora del demonio está presente en amplios espacios de la obra marcana (cinco veces). En Marcos, sobre todo, se aprecia el influjo satánico en determinadas personas como Pedro (Mc 8,33). El tema de la tentación establece la relación Satanás-peirasmos del mesías, y a juicio de Popkes, "el motivo de la lucha victoriosa de Jesús contra Satanás es esencial a Marcos"75. Ante la pregunta de si Getsemani debe ser entendida en términos apocalípticos o sapienciales, Popkes sostiene que "el contexto sugiere una situación de lucha apocalíptica"76.

\footnotetext{
${ }^{71}$ Theissen, The Gospel in Context, 197.

${ }^{72}$ En el libro de Jubileos (175-100 a. C.), las oraciones y bendiciones de ángeles y patriarcas anti-diluvianos y de la historia de Israel tienen un carácter intercesor y exorcista. La oración de Noé (Jub 10,1-3-7) está marcada por dos motivos: reconocimiento de la misericordia de Dios con Noé y petición de protección para "los hijos de los justos" en contra de los "malos espíritus" (vv. 3-5; el texto de Jub 11,16-24; y de 48,12-18, donde se describen las figuras de Abram y Moisés combatiendo a Mastema). Los vv. 16-23 resaltan la figura de Abram y muestran el poder exorcista de este, que funciona como contratipo al relato del mito de los Vigilantes; así como Abram, Moisés intercede ante el Señor: "Álcese Señor, tu misericordia sobre tu pueblo y créales un espíritu recto, no los rija el espíritu de Beliar” (Jub 1,20).

${ }^{73}$ Popkes, "peirazo", 869.

${ }^{74}$ Ibíd., 862-871.

${ }^{75}$ Ibíd., 867.

${ }^{76}$ Ibíd., 870.
} 
La única expresión en primera persona es la petición del "Abba, Padre", en el v. 36 de Mc 14,36: “AAbba, Padre!, todas las cosas son posibles para ti. Aparta de mí esta copa”. El tema de la paternidad de Dios debe ser contextualizado en relación con el motivo de la paternidad de Dios sobre los justos: los que invocan a Dios como padre son los justos. Así, por ejemplo, José -en Jose y Asenet- es presentado semejante a un ángel $(14,8)$ y, como los ángeles, "José, el hijo de Dios" (6,2.6); e igual que Enoch, José es transformado de justo en "hijo de Dios" (vv. 2,18; 5,5); los justos llaman a Dios como su Padre: "se ufana de tener a Dios como Padre [...] si es justo es hijo de Dios” (Sb 2,16.18; TestBenjamín 3,7); en el Apócrifo de José (4Q372) dice: “...mi Padre y mi Dios no me abandones en manos de los gentiles [...] hazme justicia para que el pobre y afligido no perezca”.

\section{Cristología y sentido expiatorio}

En continuidad con Mc 10,45 y Mc 14,24, la exégesis ha querido ver, en estos versículos, el modelo de la muerte noble de origen griego, vinculándolo a un sentido expiatorio de la muerte de Cristo, especialmente en círculos judeo-helenistas; por ejemplo, para de Martin de Jonge, la primitiva interpretación de la muerte de Jesús como beneficio para otros puede ser comparada con el relato de la muerte de Eleazar y sus hermanos (2M 6,18-31; $2 \mathrm{M} 7$; 4M 4-7; 8-18). En la Antigüedad, el paradigma de la muerte noble está vinculado a la muerte de los filósofos o de los héroes ${ }^{77}$. Este modelo expresa una muerte ejemplar pero en ningún caso provoca por sí misma la irrupción escatológica del Reino $(14,25)$. Por eso, se debe decir que el carácter expiatorio hay que buscarlo en otro tipo de mentalidad vinculado a ritos, como el del pharmakos, o en los ritos expiatorios judíos.

En textos cristianos rápidamente se tenderá a encontrar el sentido de la muerte de Cristo en el "perdón de los pecados", entendido en sentido moral y no escatológico. Expliquemos esto. El perdón de los pecados, en los textos tempranos, tiene un sentido escatológico, es decir, acontece el décimo Jubileo, día del Yom Quippur escatológico. Por tanto, no se trata de un perdón de los pecados reiterativo, ni individual, sino guarda relación con la predicación del Reino a los pobres y pecadores: "el Hijo del Hombre tiene potestad en la tierra para perdonar pecados" (Mc 2,5.7.9.10).

La derivación, en un sentido moral, del perdón de los pecados acontece junto con la dilación de la Parusía en los textos neotestamentarios tardíos, y sobre todo, con San Agustín. El problema de la teodicea se transforma en el problema de la antropodicea, y

\footnotetext{
${ }_{77}$ Droge, A Noble Death. Suicide and Martyrdom among Christians and Jews Antiquity, 129.
} 
la pregunta por la justicia al Dios del Reino se vuelve en la pregunta por la pureza y el pecado del hombre.

\section{La cristología como escándalo}

\section{¿Escándalo de qué?}

M. Hengel y D. Juel han sostenido con insistencia que el escándalo del cristianismo radicó en el "mesías crucificado", por el hecho de no existir antecedentes acerca de un mesías sufriente; pensamos que es equivocada esta perspectiva, pues la cuestión del escándalo radica no en la formalidad del título sino en el contexto escatológico del primer cristianismo, que remitía a la pregunta por la justicia del Reino y no específicamente a la cuestión mesiánica.

La pregunta paulina por el escándalo que significó un mesías crucificado es necesario contextualizarla en el horizonte de los diversos tipos de judaísmo que existieron durante el siglo I. Si la pregunta por la muerte de un mesías crucificado se dirige a grupos marginales, en los cuales se conocía de una justificación y expiación escatológica ya realizada, como en Qumrán, es preciso decir que los antecedentes que fueron presentados están mediados por experiencias de persecución y sufrimiento de grupos judíos que reflexionaron sobre la pasión del Hijo del Hombre a la luz de textos veterostestamentarios usados de manera pragmática por varias corrientes judías (Sal 22; Sal 69; Zc 13-14). En estos textos, la pregunta por la justicia escatológica antecede históricamente a la pregunta mesiánica y cristológica.

Tales presupuestos acercan la respuesta y dan las condiciones históricas que muestran que, incluso salvando las diferencias, el cristianismo naciente asimiló una epistemología apocalíptica -la teoría de las parábolas- para postular una salvación por medio de la fe en un mesías crucificado, el Hijo de Dios. Estos mismos textos no hablan de un mesías regio sino de un mediador de tipo profético, al modo del Hijo del Hombre, de Melquisedec, Moisés o Elías; o de figuras paradigmáticas del Justo, como Enoch o José.

La respuesta al título mesiánico de Cristo es necesario buscarla en la gran diversidad de expectativas mesiánicas y escatológicas existentes durante el siglo I y no en términos de un judaísmo normativo. Ciertamente, por una parte, Cristo crucificado fue "escándalo para los judíos y locura para los gentiles"(1Co 1,23), pero hay que decir que la idea del mesías fue bien diversa de la que esperaba el judaísmo fariseo; por otra parte, hemos demostrado que el Evangelio de Marcos adoptó una epistemología perteneciente a la tradición apocalíptica del Justo, señalando además que el evangelista ha radicalizado el sentido de la muerte de Cristo, de acuerdo con 
esta tradición como el núcleo teológico central de su obra, y ha colocado en el centro la cuestión de la mediación del Hijo, como parte de la llamada inversión escatológica. Esta se expresa como revelación de los misterios del Reino a los discípulos e ignorancia a los impíos, así como un nuevo estatuto del sufrimiento del Justo revelado por la pasión del Hijo del Hombre.

\section{Muerte de Cristo y expiación escatológica}

Han sido superadas las posiciones exegéticas extremas que se debatían acerca del origen semita o griego de las fórmulas de entrega, como lo describe Versnel: “...las diferentes opciones fueron generalmente presentadas como monolíticas y mutuamente excluyentes y consecuentemente fueron fieramente atacadas por los adherentes de las teorías rivales" ${ }^{78}$.

Como se puede demostrar, encontramos tradiciones judías que hablan de una expiación vinculada a la problemática del inicio de la era escatológica; con ello el perdón de los pecados quedó enmarcado en el horizonte más amplio de la escatología. Por ejemplo, en Qumrán -11QMelq col II,7-, Melquisedec declara la paz en el día del Yom-Quippur escatológico, en el décimo jubileo. Si ya el judaísmo enóquico había desarrollado una ruptura con el esquema sacrificial jerosolimitano, el judaísmo esenio se distingue incluso de otros textos del movimiento enóquico por el hecho de considerar que Dios, por su justicia, purifica y hace justo al hombre como un bien presente y no solo remitido a un futuro día del juicio (1QHa col. XI, 37).

Como lo demuestran los textos de 1QS col III, 1-11 -“pero Dios [...] purificó sus iniquidades y perdonó sus pecados [...] ellos adquirirán eterna vida y toda la gloria de Adán es para ellos" (CD-A col. III, 18-20)-, la justificación es identificada con un don presente en medio de la comunidad, y la expiación como un acto de purificación escatológica.

La cuestión es candente pues en esta tradición ya se hablaba de una justificación escatológica sin mesías. Entonces, queda en suspenso cómo fue entendida la novedad de la muerte de Cristo en el contexto de la escatología judía. Si la tradición de la pasión del Justo hablaba de la entrega en un contexto que integraba las cuestiones de la expiación y la justicia escatológica, el tema no radica en si el sentido de la muerte de Cristo fue escatológico o expiatorio -cuestiones que ya estaban asumidas-, sino en el punto de la función extrínseca o intrínseca del mediador escatológico, el mesías, en la cuestión del arribo del eschaton.

\footnotetext{
${ }^{78}$ Versnel, “Making Sense of Jesus' Death”, 215.
} 
Por tanto, nos hacemos la siguiente pregunta: ¿Qué aportó la muerte del Hijo del Hombre a la proclamación del Reino realizada (Mc 1,15; 15,39) ya presente en el judaísmo apocalíptico? Si ya estaba instalado el esquema escatológico de transformación del Justo en ángel, el cual también con toda probabilidad el evangelista lo ha aplicado a la muerte de Jesús (Sb 2,18; 5,5; Mc 15,39), entonces, ¿qué aportó la idea de la muerte de ese Justo junto al sufrimiento y muerte de otros justos en cuanto mediador escatológico?

La existencia de una justificación escatológica y de un paradigma de transformación del Justo en ángel en Qumrán y en movimientos apocalípticos -pero inaceptables para el judaísmo rabínico- nos lleva a sostener que el sentido originario de la muerte de Cristo está contextualizado en el paradigma apocalíptico de la pasión del Justo, por un lado, y en una identificación entre expiación de los pecados y arribo de la escatología, por el otro, tal como se venía entendiendo en textos apocalípticos y de Qumrán. En este contexto, el evangelista ha radicalizado esta perspectiva escatológica concentrando la inversión escatológica en la predicación del Reino y la muerte del Hijo del Hombre, que es el Hijo de Dios.

\section{El sufrimiento de Dios como escándalo}

Las cristologías más tempranas del Nuevo Testamento hablan del "regreso" del Hijo del Hombre sin atender al valor escatológico de su muerte y entrega por el pueblo.

Estas cristologías están absorbidas por la escatología y perviven aún en el Evangelio de Marcos (Mc 13,26; 14,62). Distintas a estas, corrientes del cristianismo -como la vinculada a la tradición premarcana en continuidad con tradiciones judías apocalípticas, que hablaban del sufrimiento y entrega de profetas y justos- aportaron los antecedentes para que la comunidad cristiana comprendiera el sentido de la muerte de Cristo en la perspectiva de la pasión del Justo. Esta continuidad se comprueba porque las comunidades cristianas usaron los mismos textos con que otros grupos judíos apocalípticos comprendieron el eschaton y confesaron su convicción acerca de la pasión y exaltación posmortem del Justo.

Con estos antecedentes el cristianismo no pasaba de ser otra secta judía más. El escándalo se explica por la radicalidad que muestran los textos de la pasión de Cristo y de la necesidad de su muerte (Mc 8,31; 9,31; 10,33) al señalar que el destino de sufrimiento y muerte del Hijo de Dios no es solo la de un justo, e introduce una nueva condición en la historia de dolor y de sufrimiento de la humanidad. Este sufrimiento ya no es desgracia sino necesidad para resucitar, pues ahora es el dolor y el sufrimiento de Dios mismo el que ha sido incorporado en la historia de sufrimiento e injusticia de toda la humanidad, de manera que -en la comunión con 
la historia de sufrimiento de cada hombre- es condición para la participación en la irrupción del eschaton.

Como hemos señalado, la cuestión mesiánica en el Evangelio se decanta por medio de la entrega del Justo que es confesado como Hijo de Dios (Sb 2,18; 5, 5; Mc 15,39). En este contexto, el estatuto del sufrimiento y muerte del Justo es radicalizado por el evangelista para mostrar que el Dios del Reino se ha revelado como debilidad y exterioridad. La confesión del centurión revela el sentido profundo del sufrimiento del Justo. La epistemología apocalíptica está en función de mostrar el misterio del secreto mesiánico, la identidad del Crucificado, esto es, el Hijo de Dios. De esta manera queda establecida la paradoja.

En un contexto escatológico del fin de la historia, el Hijo de Dios muere fuera de las murallas de Jerusalén, fuera del judaísmo, fuera del cristianismo, abandonado prematuramente por sus seguidores, y condenado por la autoridad romana. De este modo, el evangelista ha querido mostrar que el Hijo de Dios, por su muerte, no pertenece a ninguna institución humana, sino que es, en su pasión, parte de la historia de sufrimiento e injusticias humanas y paradigma de todo hombre.

Así, la epistemología de la cruz viene a expresar al Dios que se revela en el mundo como radical alteridad, en un mundo que no acepta la diferencia; viene a expresar además que la debilidad e impotencia de Dios es el medio de manifestar la fuerza y poder del Dios de la justicia; y por lo mismo, Dios se revela en los pobres y víctimas del sistema religioso judío y romano. De esta manera, la muerte del Hijo de Dios queda registrada en la historia de sufrimiento e injusticias humanas, pero paradojalmente se inscribe como un hecho de significación crítico-escatológica.

\section{Bibliografía}

Aune, David. “The Problem of the Messianic Secret”. Novum Testament XI (2016): $1-31$.

Baumester, Theodor. Die Anfänge der Theologie des Martyriums. Aschendorff Münster: Westfalen, 1979.

Black, Matthew. "The Messianism of the Parables of Enoch. Their Date and Contribution to Cristological Origins". En The Messiah. Develpments in Earliest Judaism and Christianity, editado por James H. Charlesworth, 145-168. Minneapolis (MN): Fortress Press, 2010.

Carbullanca, César. “Demonología en la apocalíptica y Qumrán”. Teología y vida LVII, 2 (2016): 211-233. 
- "La ignorancia en el Evangelio de Marcos. Un acercamiento desde la literatura de Qumrán a la teoría de las parábolas”. Theologica Xaveriana 168 (2009): 331-358.

. “¿Una teología del martirio en 1QHa y 4Q491c? Aportes para la comprensión de la cristología del Hijo del hombre joánico”. Veritas 25 (2011): 123-124.

Conzelmann, Hans. Grundriss der Theologie des Neuen Testaments (7a. ed.). Tübingen: Mohr Siebeck, 1997.

Charlesworth, James. "From Messianology to Christology: Problems and Prospects". En The Messiah. Developments in earliest Judaism and Christianity, editado por James H. Charlesworth, 3-35. Minneapolis (MN): Fortress Press, 2010. (ed.). The Messiah. Developments in Earliest Judaism and Christianity. Minneapolis (MN): Fortress Press, 2010.

De Jonge, Martin. “The Use of the Word 'Anointed' in the Time of Jesus". Novum Testamentum Vol. 8, Fasc. 2/4 (1966): 132-148.

Droge Arthur y James Tabor. A Noble Death. Suicide and Martyrdom among Christians and Jews Antiquity. San Francisco: Harper, 1992.

Dunn, James. "Messianic Ideas and their Influence on the Jesus of History". En The Messiah: Developments in Earliest Judaism and Christianity, editado por James E. Charlesworh, 365-381. Minneapolis (MN): Fortress Press, 2010.

. "The Messianic Secret in Mark". Tyndale Bolletin 21 (1970): 92-117.

France, Raymon T. The Gospel of Mark. A Commentary on the Greek Text. Grand Rapids (MI): William B. Eerdmans Publishing Company, 2002.

Frey, George y Jens Schröter. Deutungen des Todes Jesu im Neuen Testament. Tübingen: Mohr Siebeck, 2005.

Gnilka, Joachim. El Evangelio de Marcos. Vols. I y II (4a. ed.). Salamanca: Sígueme, 1999. . Teología del Nuevo Testamento. Madrid: Trotta, 1998. . Verstockung Israels. München: Kösel-Verlag, 1961.

Goppelt, Lothar. Theologie des Neuen Testaments (3a. ed.). Göttingen: Vandenhoeck \& Ruprecht, 1976.

Gübler, Marie Louise. Die Frühesten deutungen des Todes Jesu. Göttingen: Vandenhoeck \& Ruprecht, 1977. 
Haufe, G. 'Erwägungen zum Ursprung der sogenannten Parabeltheorie Markus 4, 11-12”. ET 32 (1972): 413-421.

Hengel Martin. The Atonement. The Origins of the Doctrine in the New Testament. Eugene (OR): Wipf \& Stock Publishers, 1981.

Juel, Donald. Messianic Exegesis, Christological Interpretation of the Old Testament in Early Christianity. Philadelphia (PA): Fortress Press, 1988.

Keck, Leander. “Mark 3:7-12 and Mark's Christology”. SBL 84 4(1965): 350-351. . “The Introduction to Mark's Gospel”. NTS 12(1965-66): 352-370.

Luz, Ulrich. "Basileia”. En Diccionario exegético del Nuevo Testamento (2a. ed.), editado por Horst Balz y Gerard Schneider II, 600-621. Sígueme, Salamanca, 2001. . "Das Geheimnismotiv und die Markinische Christologie". ZNW 56 (1965): 9-30.

Marcus, Joel. "Mark 4:10-12 and Marcan Epistemology”. JBL 103 (1984): 558-561. . The Way of the Lord. Christological Exegesis of the Old Testament in the Gospel of Mark. Louisville (KY): Westminster John Knox Press, 1992.

Nickelsburg, George. Jewish Literature between the Bible and The Misnah. London: SCM Press, 1981.

Penna, Romano. I ritratti originali di Gesu il Cristo. Inizi and svilupi della cristologia neotestamentaia. Milano: San Paolo, 1999.

Perrin, Norman. "The Christology of Mark. A Study in Methodology”. Journal of Religion 51, No. 3 (1971): 173-187.

Perrin, Norman y Dennis Dulling. The New Testament. An Introduction. London: HBJ Publisher, 1974.

Pesch, Rudof. Das Markusevangelium. Vols. I y II. Herders Theologischer Kommentar zum Neuen Testament. Freiburg: Herder, 1977. . L'evangelo della comunitá primitive. Milano: Paideia Editrice, 1984.

Popkes, Wiard. "peirazo". En Diccionario exegético del Nuevo Testamento (2a. ed.), editado por Horst Balz y Gerard Schneider, Vol. II, 862-871. Salamanca: Sígueme, 2001.

Räisänen, Heikki. Die Parabeltheorie im Markusevangelium. Helsinki: Finnische Exegetische Gesellschaft, 1973. . Messianic Secret in Mark's Gospel. London: T \& T Clark, 1994. 
Roloff, Jurgen. "Das Markusevangelium als Geschichtsdarstellung”. ET 3 (1969) 2: 73- 93.

Segalla, Giuseppe. La cristología del Nuovo Testamento. Brescia: Paideia, 1985.

Schreiber, Joseph. "Die Christologie des Markusevangelium”. ZThK 58 (1961): 154183.

Schweizer Eduard. "Die theologische Leistung des Mark". En Beiträge zur Theologie des Neuen Testaments, editado por E. Schweizer, 21-41. Zürich: Zwingli Verlag, 1970.

. "Mark's Theological Achievement". En The Interpretation of Mark, editado por W. R. Telford, 63- 87. Edimburgh: T\&T Clark, 1995.

. "Zur Frage des Messiasgeheimnisses bei Markus". En Beiträge zur Theologie des Neuen Testament, editado por E. Schweizer, 11-20. Zürich: Zwingli Verlag, 1970.

. "Zur Frage des Messiasgeheimnisses bei Markus". ZNW(1965): 1-8.

Sjöberg, Erik. Der Verborgene Menschensohn in den Evangelien. Lund: C. W. K. Gleerup, 1955.

Theissen Gerd. A Theory of Primitive Christian Religion. London: SCM Press, 2002. . The Gospel in Context: Social and Political History in the Synoptic Tradition. Minneapolis (MN): Fortress Press, 1991.

Versnel, H. S. “Making Sense of Jesus' Death”. En Deutungen des Todes Jesu im Neuen Testament (2a. ed.), editado por J. Frey y J. Schröther, 213-294.Tübingen: Mohr Siebeck, 2104.

Vielhauer, Philip. Historia de la literatura cristiana primitiva. Salamanca: Sígueme, 1981.

Weihs, Alexander. Die Deutung des Todes Jesu im Markusevangelium. Eine exegetische Studie zu den leidens-und Auferheungsansagen. Würzburg: Echter Verlag, 2003.

Wengst, Klaus. Christologische Formeln und Lieder des Urchristentums. Gütersloh: Gütersloher Verlagshaus Gerd Mohn, 1972. 